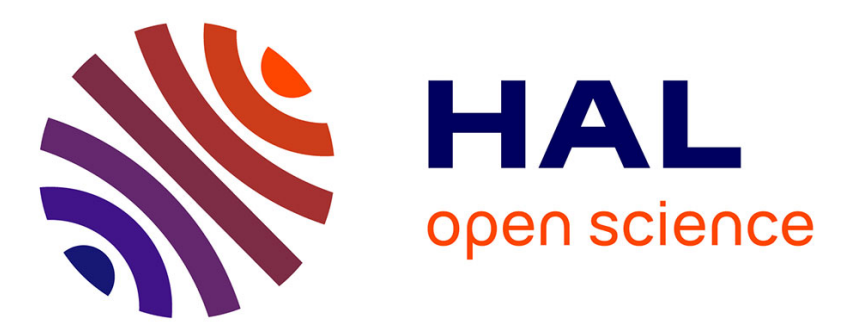

\title{
Maintenance work and the performativity of urban inscriptions: the case of Paris subway signs
}

Jérôme Denis, David Pontille

\section{To cite this version:}

Jérôme Denis, David Pontille. Maintenance work and the performativity of urban inscriptions: the case of Paris subway signs. Environment and Planning D: Society and Space, 2014, 32 (3), pp.404-416. halshs-01017569

\section{HAL Id: halshs-01017569 \\ https://shs.hal.science/halshs-01017569}

Submitted on 2 Jul 2014

HAL is a multi-disciplinary open access archive for the deposit and dissemination of scientific research documents, whether they are published or not. The documents may come from teaching and research institutions in France or abroad, or from public or private research centers.
L'archive ouverte pluridisciplinaire HAL, est destinée au dépôt et à la diffusion de documents scientifiques de niveau recherche, publiés ou non, émanant des établissements d'enseignement et de recherche français ou étrangers, des laboratoires publics ou privés. 


\title{
Maintenance Work and the Performativity of Urban Inscriptions The Case of Paris Subway Signs
}

\author{
Jérôme Denis \\ LTCI - Département Sciences Économiques et Sociales \\ (UMR 5141) CNRS - Telecom ParisTech \\ jerome.denis@telecom-paristech.fr
}

David Pontille

Centre de Sociologie de l'Innovation (UMR 7185) CNRS - Mines ParisTech

david.pontille@mines-paristech.fr 


\begin{abstract}
Urban inscriptions are performative devices that play a crucial part in urban assemblages. They mark sites, give places a name, designate directions. This paper questions such performativity by investigating the design and maintenance of subway signs in Paris. Studying backstage activities rather than user tactics, it shows that the semiotic production of space is mainly played out in standardization processes that are both oriented towards signs immutability and fueled by a daily consideration for their vulnerability. Such a posture allows us to take full account of the ontological variations of signs (which can be, for example, stable or unstable, consistent or fragile, immutable or mutable). Maintenance work, through which the agency of urban inscriptions is partially shaped, ensures the articulation of such a multiplicity.
\end{abstract}

\title{
Keywords
}

maintenance, performativity, urban assemblages, wayfinding systems 
Over the last two decades, the object of urban studies has been "decentered" (Farías, 2010), and largely overlooked domains have been investigated. Although differing in many ways, these investigations share a common preoccupation for the sociomaterial complexity of cities (Amin and Thrift, 2002; Brenner, 2004; Cresswell, 2004; Latham and McCormack, 2004; Sonda et al, 2010). The scope of research has thus been widened to such things as technical infrastructures (Graham and Marvin, 2001; Varnelis, 2009), territorialization and security devices (Adey, 2009; Kärrholm, 2007), small and mundane objects (Molotch, 2011; Molotch and Norén, 2010), and even aesthetics (Frers and Meier, 2007) and ambiances (Adey et al, 2013; Ash, 2013; Bissell, 2010; Thibaud, 2011). This movement has crystallized in the notion of urban assemblages, which has recently been at the center of debates (Brenner et al, 2011; Farías and Bender, 2010; McFarlane, 2011). Partially influenced by actor-network theory, such an interest for urban sociomateriality probably finds its most striking illustration in the book Paris, ville invisible (Latour and Hermant, 1998), which provides an in-depth investigation of the daily life of a city and explores the multitude of sites and objects that give consistency to Paris. The authors explore the intertwining of mundane artifacts, various materials, and numerous inscriptions that proliferate both backstage (in municipal workshops and offices) and in urban settings themselves, thereby uncovering the heterogeneous networks that participate in the ordering of cities.

Urban signs are among the most important of the objects and devices that make up cities. Besides having cultural and symbolic dimensions, most of them are 'performative' inscriptions in Austin's (1962) sense of the word. They 'do things' and are not genuine signifiers that represent an external reality. They contribute to the production of urban reality. Cities are partially performed by semiotic landscapes, made up of monumental lettering as well as more mundane graphical artifacts such as traffic lights, road markings, and mandatory signs. Inscriptions are constitutive of urban assemblages.

In this paper we will focus on directory signs and their performativity. In marking sites, giving places a name, designating directions, these signs are what Garfinkel (1996) terms "territorial organizational things" and what Deleuze and Guattari (1987) call "mots d'ordre" ('order words'). They display descriptions that are at the same time instructions, authorizations, and prohibitions. As disciplinary devices (Ureta, 2013), directory signs contribute to "modes of ordering" that perform and maintain "spaces of flows" (Knox et al, 2008) and are crucial components of the "machinery of placement" that equip mobility practices (Amin and Thrift, 2002).

There are multiple ways of studying directory signs' performativity. The most frequent consists in focusing on inhabitants' wayfinding practices and relations to signs. Research on the topic has pointed to the complexity and inventiveness of the uses of these sets of signs. Scholars have, for example, systematically documented the on-site adjustments made to find one's way using directional signs (Sharrock and Anderson, 1979; Timpf, 2002). Studies have also focused on uses in order to show that certain wayfinding systems fail to guarantee the success of travel routes and that their utilization actually consists largely in their combination with other resources on site (Vertesi, 2008). More generally, these studies have underlined the process of shaping what Lave (1988) calls "settings"; that is, temporary and locally pertinent frameworks for action that combine material elements available in the environment (what Lave terms the "arena"). 
Such a user-centric perspective is largely asymmetrical. Indeed, in these studies, while user activities are rich, and characterized by ingenuity, inventive arrangements, and complex adjustments, the environment itself is pared down, and regarded as a stable, if not abstract, scenery. In this paper we assume that by sticking to user practices only, scholars miss important aspects of sign performativity in urban assemblages, and especially overlook the role of maintenance and repair (Brand, 1994; Edensor, 2011). Sets of urban signs certainly do not provide inert sociomaterial frames, which are 'naturally' available in the environment and activated through the action of passersby only. Numerous backstage activities (Goffman, 1959) are conducted in order to manage the components of urban settings. The mere presence and persistence of signs in a given space are the result of a continuous process carried out by day-to-day practices - from design to maintenance-that we must study in detail if we wish to understand the role of inscriptions in the production of public settings. We will show that such a semiotic production is mainly played out in standardization processes. But if such processes are oriented towards the stability and consistency of signs, they draw on a daily consideration for the vulnerability of signs. Studying backstage activities and maintenance work (Graham and Thrift, 2007; Henke, 2000) allows thus to respecify the issue of sociomateriality by focusing on dimensions largely overlooked until now: fragility and instability.

We draw on the case of the Paris subway system, using the results of an ethnographic fieldwork in the departments dedicated to signage design, normalization, and maintenance within the Régie Autonome des Transports Parisiens (RATP). Taking a practice-based perspective (Gherardi, 2012), this fieldwork combines in-depth interviews with RATP employees, the gathering of various internal documents (such as spec sheets, press material, internal media documents, graphic standards manuals, and information leaflets), and the shadowing of maintenance workers who put up, repair, and replace Paris subway signs every day. We first expose two characteristics that are crucial to understanding the nature of subway signs: immutability and spatiality. We then show that these features are not inherent material properties by analyzing the various springboards that ensure the day-to-day maintenance of the wayfinding system. Finally, we highlight the unstable side of standardized graphic artifacts and show how maintenance can help to renew our understanding of the performativity of urban inscriptions.

\section{Performativity and the Stability of Inscriptions}

Actor-network theory is particularly useful for exploring the conditions of the performativity of graphic artifacts. From the publication of Laboratory Life (Latour and Woolgar, 1979) onwards, inscriptions have been at the center of actor-network-theory studies, much of which foregrounds the role of the various technical tools used for coding, marking, reading, and writing practices. The repeated actions of these inscription devices have been described as articulated operations that progressively give scientific claims their substance. Furthermore, the value of inscriptions is conceived in a relational fashion. Their consistency, reliability, and strength are attributed to the layout of the scientific laboratory, with its specific configuration of researchers, apparatuses, machines, desks, equipment, specialized reading material, and technicians. 
Such an approach has been extended to urban settings and their signs. Throughout their backstage exploration of Paris, Latour and Hermant (1998) show how activities such as the designation of streets and the placement of street signs are caught up in a vast network of written traces and administrative services woven together: files, cardboard folders, forms, statement notes, maps from the Voirie (the roads department), from the land registry, from property documentation services, from nomenclature divisions ... . The success of street designation is seen here as the result of these various inscriptions coming into alignment with one another. Firmly attached, they then mutually provide the substance for each street name.

From an actor-network-theory point of view, the strength of an utterance thereby never lies in the inscription itself. In this semiotic conception, each element within the network holds a specific position, acting functionally with regard to the others. The relative syntactic positions of the entities contribute to the network's overall action. The performativity of artifacts (whether graphic or not) depends on another characteristic. As we have just seen, performativity is foremost linked to the stability of the relations the objects maintain within a network. But this stability is actually seen as the condition for their mobility. For Latour (1986), the strength of artifacts is conditioned by the artifacts' capacity to become 'immutable mobiles"; that is, their capacity to move from one place to another without changing their state or losing their form.

The Paris subway wayfinding system is a fine example of how urban inscriptions can undergo such a stabilization process. In the early 1990s a group of people from various backgrounds (including cartographers, architects, and designers) rallied to present to the RATP $^{1}$ what they saw as an obvious flaw in the signage system: the corridors of the subway were covered with a hodgepodge of signboards that differed from one station to the next. In their eyes, these extreme variations led to disorder and needed to be homogenized. This observation was drawn out further and the team was eventually tasked with fundamentally reorganizing - or rather simply organizing, as they put it - the entire signage system (Denis and Pontille, 2010a).

For the first time, the signs were standardized in minute detail in an ambitious, large- scale project instigated by the team. In order to homogenize the boards, a series of standard units was created in an attempt to respond to every possible situation in the various public areas. For every type of sign, exhaustive rules were laid out for dimensions, materials, colors, and inscription design. The same was true for the vocabulary, terms, spelling, and abbreviations used for names of stations, directions, exits, connections, and various messages providing information. With the forms of each sign strictly structured and each component part set to the millimeter, the elements of the signage system were stabilized and standardized. In even the most varied situations, the once unbalanced graphic elements were made steady. From 1996 on, each signboard became a standardized immutable object.

The renovation project was founded on the idea of grouping all of the boards into a single system. The term 'signage system' (in French, 'signalétique') indeed incorporates this notion of an assemblage. The stability provided by the standardization process was therefore put to

\footnotetext{
1 The RATP is the public transport operator responsible for the Paris subway network.
} 
the service of creating interdependence between the graphical units. Not only the units themselves were identical-so were their materials. For example, the color assigned to each subway line remained identical irrespective of the sign's materials. In the same way, for all of the signs, dark blue writing on a white background was set to indicate the directions of the different lines, whereas white lettering on a blue background was used for the names of stations and exits. The signboards were thus made immutable in the sense that each element was designed to remain consistent with the others throughout the system. But instead of producing immutable mobiles, the standardization of subway signs enhanced their very immobility. Their performativity is indeed closely linked to a particular relation to space.

\section{Spatiality and Displayed Inscriptions}

Two strands of research are particularly useful for understanding the importance of space in analyzing the performativity of displayed inscriptions. First, Scollon and Scollon (2003) have developed a program for studying 'geosemiotics' in which they deal directly with this question. Proposing a break with traditional semiology, which limits analyses to the interpretation of signs 'themselves', they argue for a study of signs 'in place'. A primary focus of geosemiotics is indexicality, which is analyzed through the study of sign emplacement. The problem is illustrated well by the example of a fire exit sign (Scollon and Scollon, 2003, pages 28-31). The arrow indicates the direction in which to run, and the icon showing a person fleeing the flames is also indexical, since the person runs in the same direction as the arrow. A sign of this kind is of little meaning in storage at the factory or in the hands of the worker preparing to put it in place. Only once it is installed in its final, precise position will the sign convey meaning. In this sense, the sign's strength and meaning derive from its spatial properties. Precisely because the sign shares space with that which it designates, it may be considered performative.

Second, in her theory of writing acts, Fraenkel (2006) proposes-though from a markedly different perspective - to home in on the notion of space when analyzing the performativity of inscriptions. She begins with an in-depth discussion of the work of Austin (1962), who abandons performativity after the seventh How to Do Things with Words lecture. Fraenkel explains that Austin's differentiation between performative and constative utterances is in fact an impasse because it neglects the qualities of written utterances, limiting the act of enunciation to the present moment. Thus, Fraenkel (2006) shows how in Austin's example of a 'beware of the dog' sign, the sign is imagined as an oral utterance that would serve the exact same warning purposes as a theoretical person present on the scene. For Fraenkel, Austin therefore misses the conditions of the sign's performativity. First, the sign is not an utterance floating about and waiting for an enunciator; rather, it is positioned somewhere, and its placement is completely inseparable from its performative dimension. Second, the sign is an object, and its form and substance are essential to its capacity for action. These two elements build on the work of Scollon and Scollon (2003), emphasizing the situated nature of the performativity of inscriptions.

Fraenkel insists, however, on a third point. It is upon hanging the 'beware of the dog' sign at the gate of a house that the house becomes a protected place. In the same way, in placing a warning sign near a sharp bend in the road, the bend is performed as a dangerous turn. In 
this line of thinking, the performativity of inscriptions is also dependent on the act of positioning. A particular site is modified upon the addition of an inscription whose emplacement and materials are crucial. In other words, in these cases, the inscription performs the space in the same way that, for Simmel (1994 [1909]), the bridge performs the banks of the river. These two approaches examining the relationships between space and graphic artifacts help to speak more specifically about the performativity of the signage system in the Paris subway. The standardization processes applied to the signs indeed not only rendered them immutable, but also dealt directly with their emplacement. A unique spot was attributed to each sign in the system throughout the different stations. Redesigned and standardized, subway signs have become immutable immobiles. Upon the introduction of this series of standardized, ordered signs, the underground public transportation spaces were therefore considerably transformed, and the passengers' environment was stabilized as it never before had been. The standardization of the system's graphic elements has performed an environment within which "the distinction between the building and its signs, between the text and the territory, becomes indistinct" (Fuller, 2002, page 236). At each station the standardized signboard units obey identical rules; wherever a passenger happens to enter the transportation network, the characteristics of the environment he or she observes are meant to be similar.

The generalized similarity achieved by these processes aside, the repetition of standardized elements throughout the stations also creates differences. While stabilizing the surrounding environment, the signage system also divides the space into regions. Equipped with its specific graphical units, the Paris subway differentiates itself from other subway systems and has split off from the SNCF rail network, ${ }^{2}$ with which it nevertheless shares certain spaces. ${ }^{3}$ From the point of view of the subway system alone, the stabilization and ordering of the environment also means a strict division at each site, reaching far beyond the distribution of stations throughout the city. Each station is divided into zones: entry halls with neighborhood and network maps; corridors with directional arrows, subway line numbers and the names of the travel directions; platforms with network maps, connections, station names, and the names of each station exit. This differentiation within sites is applied to the entire network: the same distinct zones are repeated from station to station, thus creating standard spaces despite their architectural disparities. Hence, the new signage policy has played a crucial role in the territorialization (Brighenti, 2010) of subway spaces, articulating three of the territorial processes identified by Kärrholm (2012): stabilization, singularization, and separation.

Such territorialization is not an end in itself: it is entirely dedicated to fluidity. The standardized wayfinding system and the stabilized, singularized, and separated environment it has performed are a paradigmatic case of immobile infrastructures dedicated to mobility (Amin and Thrift, 2002; Lash and Urry, 1994): they are meant to provide stable, resilient support for large-scale movement of people and objects. At the same time, such a territorial

\footnotetext{
2 The SNCF (Société Nationale des Chemins de fer Français) operates France's national rail services (including the TGV or high-speed network) and some regional trains.

${ }_{3}^{3}$ These shared spaces are at the center of significant debates on how to guarantee a smooth transition from one transport system to another despite a change in signboard systems. They are good illustrations of how a single site may be treated materially by different territorial productions at the same time (Kärrholm, 2007).
} 
strategy gives passengers a specific position within the sociotechnical network. The overhaul of the signage system has established a policy of attention in the stations that implies a specific relationship to the graphical landscape through which passengers are made essential partners in the production of a fluid mobility (Denis and Pontille, 2010c). Therefore, the performativity of urban inscriptions is a territorial performativity, in which the stabilization and spatialization of signs are essential. However, this gives only a partial view of graphical territorialization, suggesting that the territory is performed once and for all. This is not the case, of course. Though standardized, the arrows, icons, destination names, or line numbers are not guaranteed to remain visible to passengers day after day. Their stability and permanence have to be taken care of.

\section{Stability and its Various Springboards}

Numerous operations are underway to make provision for signage within the RATP, where, with the exception of those working specifically on the placement and design of station signs, ${ }^{4}$ the majority of the 45000 salaried workers have other concerns. One method of making provision for signage is to add to RATP staff's existing workload. This is the case, for example, of the employees in charge of monitoring stations. These employees are asked to supervise the condition of the signboards, and note cases of degradation or absence in the same way that they are also to note wall graffiti, unpleasant odors, or furniture damage. Standard forms and organizational proceedings clearly speak of this obligation (for example, in the reports passing from the stations to the maintenance services), but it is also present in less formalized exchanges. During maintenance operations, for example, a maintenance worker might come across a missing or faulty signage element that has not already been pointed out. The employee would then look to inform the station superintendent of the situation, taking the opportunity to emphasize the fact that since the superintendent's job includes signboard supervision, his or her role has not been completely fulfilled on this occasion. In a similar fashion, the two employees in charge of standardization often find themselves having to remind subway line managers or communications officials of signage standards, asking them to respect a particular layout or to use a certain color rather another.

In all of these cases, it is a question of including the-stable and standardized-signage system in the tasks of employees not otherwise inclined to take it into consideration. Through various intermediary actors, the system becomes a clearly defined, resistant object with certain constraints on the activities of employees. Contrary to their neutral appearance, the processes of signboard maintenance are essential and difficult to carry out. The subway signage system is no simple matter. To make this clear, we may point to the Paris Renouveau du Métro (subway renewal), a series of station renovation projects contracting outside companies to refurbish Paris's metro stations, including their signage units. However, when the first stations were finished, a number of problems arose. An entirely renovated station was considered 'complete' without a single signboard. Neither the construction managers nor the RATP employees taking delivery of the project had deemed the station unfit for opening. The signboard units had been defined, their quantity and location having

\footnotetext{
${ }^{4}$ At the time of our study, the RATP had two employees in charge of standardization, with ten working on subway signs installation and maintenance.
} 
been decided upon in the station specifications, but this was not enough to ensure the implementation of the signage system. Since this particular episode, measures have been taken to ensure that the signage system 'matters' - that is, that its presence or absence makes a difference (Cooren, 2004). In addition to the standard contractual documents, an RATP representative now oversees the renovation work and, as a condition of validation and payment, checks that the signboards are present in the station and that they conform to standards.

This process takes an interesting turn when signage system spokespersons in the organization find themselves confronted with different areas they consider to be in competition. The reinforcement of the subway signage system may then be seen, as these spokespersons put it, as a 'struggle'. It is less about fostering concern for the signboards than it is about rendering their presence imperative and unquestionable in underground transport spaces. In the case of the RATP, one of the most explicit battles is against the advertising division. As we have seen, the signage standardization process has involved organizing spaces: it has homogenized not just the design and content of the graphical units but also their placement in the stations. Over the course of this process, specific locations have been set aside for advertisements. In this sense, the battle is already over: the two graphic forms are to coexist stably. However, the advertising department also regularly proposes events and 'below the line' experimental advertising campaigns, which, in the eyes of signage system proponents, constitute a direct threat. The threat is particularly significant since the arguments put forth by the two groups are very imbalanced. The advertising locations are represented by the RATP advertising division, where every square meter represents financial gain. The signage spokespersons fight back with principles, untranslatable into numbers and even less so into financial consequences. The struggle takes on various forms: a signage proponent might appear in person to react to a particular advertising project, or documents might be written in an attempt to define the best strategy for peaceable coexistence.

During our study one of the standardization managers was tasked with writing guidelines for the proper application of stickers within public spaces, since the practice of covering parts of the space with advertising stickers had become common and was met with criticism. The goal was clear: to control, to the greatest extent possible and without value judgments, the process of creating and commercializing the underground advertising space. This last aspect illustrates the extent to which the organization of the relations between signs and spaces may become a political matter. Each space, particularly each public space, has the potential for housing a multiplicity of graphic forms. Elements of the signage system are not the only visual units liable to populate subway stations. The signage system's place among other 'species of inscriptions' is not self-evident and must be obtained through ongoing struggles. The Chicago School perspective may help in understanding this kind of competition (Hughes, 1936; Park, 1936). It is indeed possible to approach transportation spaces as territory to be conquered. Because they appear to have limited room for display, the spaces become the 
theatre of competition between various types of inscriptions all seeking to occupy it. ${ }^{5}$ In this sense, the performativity of urban inscriptions must be understood not just as the result of a stabilized relationship between signs and spaces, but also as a fragile balance in the midst of a particular graphic ecology (Denis and Pontille, 2010a).

More generally speaking, the 'backstage' processes described here encourage us to reexamine the role of immutability in signboard performativity. Such immutability cannot be considered as a merely mechanical consequence of normalization and standardization procedures. Immutability is a relative characteristic: for the signage system to remain stable and for it even to exist at all, it is not enough to divide it into standard units with carefully documented content, colors, and shapes. There must also be a way of drawing attention to it. The wayfinding system needs to become a matter of concern; it must find a place within existing organizational processes. In other words, if we can apprehend the performativity of this kind of apparatus via the attention it draws from its users (Denis and Pontille, 2010c), we can also safely say that much depends on a symmetrical form of attention that plays out 'backstage'. If the different units are to become truly fixed and immutable, they need to receive a certain professional consideration distributed throughout the different spaces and activities. Their stability therefore depends on a multitude of small processes, the articulation of which is a task in itself.

\section{Stable Apparatus, Unstable Objects}

Shedding light on the delicate sociotechnical assemblages that guarantee the everyday immutability of the signage system is only a first step in analyzing the performativity of urban inscriptions. As we have seen, making individuals aware of the signs that make up the wayfinding system is not a once-and-for-all event. What matters is rather the day-to-day process of monitoring, repairing, and replacing signboards. Beyond the distribution of the tasks necessary for the system to run smoothly, the reiteration of these tasks is in itself part of what is at stake. The immutability of signs and the spatial order that is supposed to come of it are thus never actually achieved, but are constantly in play, distributed among the work patterns of each station attendant, maintenance worker, standardization manager, and others.

This is a central aspect of the idea of maintenance. To maintain is to guarantee stability, to provide things with a level of permanence they do not possess 'naturally'. We propose to make this maintenance work a focal point in the analysis of the performativity of inscriptions, refusing to accept the supposedly intrinsic immutability of graphic artifacts as an explanatory principle. With this theoretical shift, we return to Garfinkel's (1967) principles of ethnomethodology and Goffman's (1986) theory of social order from the point of view of objects. These two authors insist on the necessity of relocating the fundamental principles of social order in face-to-face situations. Interaction order always occurs as a situated accomplishment-in other words, there are a very small number of things in the world that

\footnotetext{
${ }^{5}$ The most striking example here is, without a doubt, graffiti. The battle surrounding graffiti is very different from the advertising battle in that it is carried out not only backstage through charters and standard documents, but also directly in the stations. The methods used to paint graffiti, but also those used to remove it, bring very specific issues into play, notably material degradation.
} 
are definitively identified or instated and upon which we would agree if we were asked to provide details. Cooren (2010) develops this approach, illustrating that there exists no principle, no rule of organization of social relations, that does not require repeated forms of instantiation. Every time, they must be displayed, made to exist, "each another next first time" (Garfinkel, 2002, page 98).

As we have seen, Latour's (1986) key contribution to these theoretical viewpoints is his discussion of stabilization dynamics and the crucial role that artifacts play in them. However, when we observe the everyday practices of the signage system's normalization and maintenance operations, it is also clear that the total opposite is to be avoided. Considering stability as a corollary of every artifact would be proof only of narrow-minded materialism. The material properties of objects are not intrinsic, but rather are updated on a constant basis (Brand, 1994; Edgerton, 1999). As Henke (2000) and Graham and Thrift (2007) have demonstrated, it is particularly rewarding to take the same perspective on objects that Garfinkel (1967) and Goffman (1959) take on ordinary exchanges and the vulnerability of the interaction order. Material order must also be cared for and repaired.

Adopting this viewpoint does not mean that things - in this case, inscriptions - are not stable and cannot organize the environment. It does mean, however, that it is possible to study in greater detail the relative character of their immutability. Though the wayfinding system is constantly being brought to the attention of many within RATP, the graphical units themselves are not stable for every passenger at every moment. Their stability is only a displayed stability, directed at the subway riders and oriented toward them. We think that understanding the forms of artifact performativity requires that this dimension of objects be recognized. Just as identity for Goffman (1959) is always a projected identity, a performance that is possible only because of the backstage activities on which it relies, the identity of objects - their immutability-must be observed as the fragile result of constant maintenance work.

But what exactly is this work, and what can it teach us? Sociological studies traditionally respond to these questions focusing on humans. They attempt to shed light upon the activities that shape the world's infrastructures on a day-to-day basis. In these cases the sociologist's job is to surface the invisible work that makes it possible to rediscover "the mess obscured by the boring sameness of the information represented" (Star, 1999, page 385). This gesture runs parallel to the numerous attempts made to emphasize how ordinary work is "practically accomplished" (Gherardi, 2012) and highlights the depth of day-to-day activities compared with the formal representations that guide their prescription (Orr, 1996). Attention here is paid to the role of invisible workers, particularly their capacities to improvise and come up with in situ solutions which are essential to repair and maintenance work (Henke, 2000).

But the study of maintenance work is also valuable for the analysis of objects themselves. Examining the work of the station superintendents and maintenance workers is a means of studying the less obvious places and moments of the signs' existence. In so doing, we discover a mode of existence in which signs are no longer, in Heideggerian terms, 'ready-tohand' - that is, no longer visible upon use, but 'present-at-hand', considered independently of their ordinary use when they are out of order (Verbeek, 2004). Indeed, this perspective 
entirely changes the way the performativity of inscriptions may be understood. It is not merely the stability and durability of the signs that must be examined here, since for those who repair and monitor them, signs are never truly stable. Their colors fade, they wear out, their surface is attacked by mold, they are stolen, they break ... . Awareness of the instability of the signboards and the changes they undergo is at the heart of these workers' jobs. It is the essence of their expertise. And this is precisely what is at stake when they ask their colleagues to remain sensitive to changes in the wayfinding system. Maintenance lies in the capacity of workers to become attentive to wear and tear, to perceive the minute traces of a missing sign, and to realize that a corridor is no longer a corridor if one of its signs is absent. Maintenance work therefore consists in identifying thresholds of variability in a system that is intended, for the sake of its users, to be immutable.

In highlighting the importance of such work, our point of view is not in principled, definitive opposition to the vocabulary of immutability. Rather, it seeks to show that such a vocabulary is not the only pertinent register for the study at hand. To this end, we follow post-actornetwork-theory studies in their insistence on objects' multiplicity (De Laet and Mol, 2000; Law, 2002; Mol and Law, 1994). Using the case of one technological innovation (actornetwork-theory's preferred field of research), De Laet and Mol (2000) have illustrated that the success of a pump in the deserts of Zimbabwe does not depend on operations that close it off to stabilized forms and functions. On the contrary, it is precisely thanks to openness to change, and especially thanks to maintenance arrangements, that the desert pump and its uses have been developed extensively. In a detailed discussion Law (2002) builds on De Laet and Mol's (2000) conclusion, and argues that if we accept that objects are multiple, and if we want to explore the variety of their ontologies, notions such as 'network' and 'immutability' do not suffice. Here, we propose the same: in considering the largely invisible work needed to maintain the signage system, the artifacts become apt for an analysis that takes full account of their ontological variations. The signs are immutable and mutable, immobile and mobile, from one situation to another. ${ }^{6}$ Maintenance shows that we cannot address the question of urban inscriptions' performativity by listing more or less intrinsic 'properties' of signs. On the contrary, performativity appears here to rely on the intertwining of different properties. At the heart of maintenance work is a series of concrete operations that enact the day-to-day stability and permanence of graphic objects in identifying, and dealing with, their constant transformations.

\section{Conclusions}

Urban inscriptions are performative in that they participate in the organization of the world. Their presence in public spaces is an operator of territorialization: numerous signs are dedicated to channeling traffic, disciplining bodies, and ordering space. In shedding light on the backstage of this semiotic territorialization, we have shown that the performativity of

\footnotetext{
6 Of course, we must not reduce the variety of ontologies at the invisible boundaries between user spaces and 'backstage' action. In following the workers for whom sign installation is an everyday activity, it becomes clear how the signs regularly shift from one ontology to another as they progress in the installation process (Denis and Pontille, 2010b). Similarly, following passengers, or sign collectors, or graffiti artists, we would certainly discover other ontologies enacted by completely different practices.
} 
urban inscriptions is grounded neither in intrinsic properties that would naturally bring discipline and order, nor in their users' eyes only. The stabilization of Paris subway spaces performed by the overhauled wayfinding system draws on numerous springboards that ensure the consistency and omnipresence of signs on a daily basis-what we called maintenance work.

In the terms of Austin's (1962) model of performativity, our analysis has therefore questioned a routinely hidden side of what he calls the "felicity conditions" of urban inscriptions. For Austin, felicity conditions are crucial elements of performativity, which does not consist of utterances and their structure alone. They include all the contextual elements that ensure the success of performative utterances. Yet, in this model, felicity conditions remain relatively unchanged, and are made up of conventional, stabilized procedures and principles. Our analysis of maintenance work follows the recent discussions that reexamine the notion of felicity conditions as concrete sociomaterial situations (Butler, 1997; Callon, 2007). Since it consists in taking care of instability and material vulnerabilities, maintenance is resistant to standardized procedures (Orr, 1996) and sheds light on the irremediably changing character of the felicity conditions of subway signs.

Moreover, our study shows that, apart from being a matter of spatial features (Scollon and Scollon, 2003), urban inscriptions performativity is also a matter of temporality. Among their felicity conditions, the circumstances of their permanency are crucial, though overlooked, aspects. Throughout his lectures, Austin (1962) uses a series of well-known examples (baptism, marriage, engagement) to anchor the definition of performativity in an instantaneous action, making it possible to distinguish between a 'before' and an 'after'. In questioning urban inscriptions, we emphasize rather the enduring properties of graphical artifacts. The performativity of urban inscriptions is a matter of duration. Their strength relies on their capacity to be continuously available and to remain immutable and immobile.

Such a durable performativity does not lie in some inherent material features, but rather draws on continuous maintenance work that enacts it. Such work engages a certain ecology of visible and invisible (Star and Strauss, 1999). Indeed, it seems that the performativity of urban inscriptions relies on erasing the fragile arrangements that make their immutability possible, and on the continuous work it requires. For urban inscriptions to remain visible, always identical, their maintenance is made invisible. Hence, urban inscriptions do not perform a stabilized environment only. They also perform regions: in actually designing a decorum oriented toward their users, they also give shape to its backstage (Goffman, 1959). The conditions of their felicity depend just as much on the visibility of the former as on the invisibility of the latter.

Our study also attempts to contribute to the understanding of urban assemblages, shedding light on overlooked entities and practices. Our aim has been to encourage reflections on urban inscriptions that go beyond the focus, inspired by the works of de Certeau (1984) and Lefebvre (1991), on users and their tactics. Indeed, in considering user practices only, there is a risk of perpetuating the boundary between active users on one side and inert objects on the other, and of keeping maintenance work invisible. Moreover, user-centric approaches may lead to a perspectivist description of objects and their performativity, a description that concentrates on interpretation processes and apprehends objects as "singular, intangible, 
untouched" (Mol, 1999, page 76). In questioning the processes of stabilization of the Paris subway wayfinding system and the maintenance practices on which they are based, we have underlined the multiplicity of signs themselves, and the role of such a multiplicity in their performativity. It is through the articulation of their various ontologies (such as stable and unstable, consistent and fragile) that urban inscriptions agency is shaped. This study thus invites readers to go beyond the description of sociomaterial heterogeneity of cities, by investigating the very multiplicity of urban assemblages and uncovering the role of maintenance work in their daily production.

\section{Acknowledgments}

This paper is based on research that was part of the 'Écologies et Politiques de l'Écrit' program, funded by the National Agency for Research in France (ANR-05-BLAN-0272-02). We are very grateful to Jill McCoy for her professional commitment in the translation of this paper. We also thank two anonymous reviewers for their helpful comments on a previous version of this paper.

\section{References}

Adey, P, 2009, "Facing airport security: affect, biopolitics, and the preemptive securitisation of the mobile body" Environment and Planning D: Society and Space 27(2) 274-295.

Adey, P, Brayer, L, Masson, D, Murphy, P, Simpson, P, and Tixier, N, 2013, “'Pour votre tranquillité': Ambiance, atmosphere, and surveillance" Geoforum 49 299-309.

Amin, A and Thrift, N eds., 2002 Cities: Reimagining the Urban (Polity Press, Cambridge).

Ash, J, 2013, "Rethinking affective atmospheres: Technology, perturbation and space times of the non-human" Geoforum 49 20-28.

Austin, J L, 1962 How to Do Things with Words (Oxford Univeristy Press, New York).

Bissell, D, 2010, "Passenger mobilities: affective atmospheres and the sociality of public transport" Environment and Planning D: Society and Space 28(2) 270-289.

Brand, S, 1994 How Buildings Learn: What Happens After They're Built (Penguin Books, London).

Brenner, N, 2004 New State Spaces: Urban Governance and the Rescaling of Statehood (Oxford University Press, USA, Oxford).

Brenner, N, Madden, D J, and Wachsmuth, D, 2011, "Assemblage urbanism and the challenges of critical urban theory" City 15(2) 225-240.

Brighenti, A M, 2010, "On territorology: towards a general science of territory", Theory Culture \& Society 27(1), pp. 52-72.

Butler, J, 1997 Excitable Speech. A Politics of the Performative (Routledge, New York).

Callon, M, 2007, "What Does It Mean to Say that Economics is Performative?", in Do Economists Make Markets? On the Performativity of Economics Eds D MacKenzie, F Muniesa, and L Siu (Princeton University Press, Princeton, N.J.), pp 311-357.

Cooren, F, 2004, "Textual Agency: How Texts Do Things in Organizational Settings" Organization 11(3) 373-393.

Cooren, F, 2010 Action and Agency in Dialogue: Passion, Incarnation and Ventriloquism (John Benjamins, Amsterdam / Philadelphia). 
Cresswell, T, 2004 Place: A Short Introduction (Blackwell, Malden, MA).

Deleuze, G and Guattari, F, 1987 A Thousand Plateaus: Capitalism and Schizophrenia (Continuum, London / New York).

de Certeau, M, 1984 The Practice of Everyday Life (University of California Press, Berkeley). de Laet, M and Mol, A, 2000, "The Zimbabwe Bush Pump: Mechanics of a Fluid Technology" Social Studies of Science 30(2) 225-263.

Denis, J and Pontille, D, 2010a Petite sociologie de la signalétique. Les coulisses des panneaux du métro (Les Presses des Mines, Paris).

Denis, J and Pontille, D, 2010b, "Placing Subway Signs: Practical Properties of Signs at Work" Visual Communication 9(4) 441-462.

Denis, J and Pontille, D, 2010c, "The Graphical Performation of a Public Space. The Subway Signs and their Scripts", in Urban Plots, Organizing Cities Eds G Sonda, C Coletta, and F Gabbi (Ashgate, London), pp 11-22.

Edgerton, D, 1999, "From innovation to use: Ten eclectic theses on the historiography of technology." History and Technology, an International Journal 11(2) 37-41.

Edensor, T, 2011, "Entangled agencies, material networks and repair in a building assemblage: the mutable stone of St Ann's Church" Transactions of the Institute of British Geographers 36(2) 238-252.

Farías, I, 2010, "Introduction: decentring the object of urban studies", in Urban Assemblages. How Actor-Network Theory Changes Urban Studies Eds I Farías and T Bender (Routledge, London / New York), pp 1-24.

Farías, I and Bender, T eds., 2010 Urban Assemblages: How Actor-Network Theory Changes Urban Studies (Routledge, London / New York).

Fraenkel, B, 2006, "Actes écrits, actes oraux: la performativité à l'épreuve de l'écriture" Études de communication (29) 69-93.

Frers, L and Meier, L eds., 2007 Encountering urban places: visual and material performances in the city (Ashgate, London).

Fuller, G, 2002, "The Arrow - Directional Semiotics: Wayfinding in Transit" Social Semiotics 12(3) 231-244.

Garfinkel, H, 1967 Studies in Ethnomethodology (Prentice-Hall, Englewood-cliffs).

Garfinkel, H, 1996, “Ethnomethodology's program” Social Psychology Quarterly 59(1) 5-21.

Garfinkel, H, 2002 Ethnomethodology's Program. Working Out Durkheim's Aphorism (Rowman and Littlefield Publishers, New York).

Gherardi, S, 2012 How To Conduct A Practice-Based Study (Edward Elgar Pub, Northampton, Mass.).

Goffman, E, 1959 The Presentation of Self in Everyday Life (Doubleday, New York).

Goffman, E, 1986 Frame Analysis: An Essay on the Organization of Experience (Northeastern University Press, Boston).

Graham, S and Marvin, S eds., 2001 Splintering Urbanism. Networked Infrastructures, Technological Mobilities and the Urban Condition (Routledge, London / New York).

Graham, S and Thrift, N, 2007, "Out of Order: Understanding Repair and Maintenance" Theory, Culture \& Society 24(3) 1-25.

Henke, C R, 2000, "The Mechanics of Workplace Order: Toward a Sociology of Repair" Berkeley Journal of Sociology 44 55-81. 
Hughes, E, 1936, "The Ecological Aspects of Institutions" American Sociological Review 1(2) 180-189.

Kärrholm, M, 2007, "The Materiality of Territorial Production: A Conceptual Discussion of Territoriality, Materiality, and the Everyday Life of Public Space" Space and Culture 10(4) 437-453.

Kärrholm, M, 2012 Retailising Space. Architecture, Retail and the Territorialisation of Public Space (Ashgate, London).

Knox, H, O’Doherty, D, Vurdubakis, T, and Westrup, C, 2008, "Enacting airports: space, movement and modes of ordering" Organization 15(6) 869-888.

Lash, S and Urry, J, 1994 Economies of Signs and Space (Sage Publications, London). Latham, A and McCormack, D P, 2004, "Moving cities: rethinking the materialities of urban geographies" Progress in Human Geography 28(6) 701-724.

Latour, B, 1986, "Visualisation and Cognition: Drawing Things Together" Knowledge and Society: Studies in the Sociology of Culture and Present 6 1-40.

Latour, B and Hermant, E, 1998 Paris ville invisible (La Découverte / Les Empêcheurs de penser en rond, Paris).

Latour, B and Woolgar, S, 1979 Laboratory Life: the Social Construction of Scientific Facts (Sage, Beverly Hills).

Lave, J, 1988 Cognition in Practice. Mind, Mathematics and Culture in Everyday Life (Cambridge University Press, Cambridge).

Law, J, 2002, "Objects and Spaces" Theory, Culture \& Society 19(5/6) 91-105.

Lefebvre, H, 1991 The Production of Space (Blackwell Publishing, Paris).

McFarlane, C, 2011, "The city as assemblage: dwelling and urban space" Environment and Planning D: Society and Space 29(4) 649-671.

Mol, A, 1999, "Ontological Politics. A Word And Some Questions", in Actor Network Theory and After Eds J Law and J Hassard (Blackwell Publishers, Oxford), pp 74-89.

Mol, A and Law, J, 1994, "Regions, networks and fluids: anaemia and social topology" Social Studies of Science 24(4) 641-671.

Molotch, H L and Norén, L, 2010 Toilet: Public Restrooms and the Politics of Sharing (New York University Press, New York).

Molotch, H, 2011, "Objects in the City", in The New Blackwell Companion to the City Eds S Bridge and S Watson (Blackwell, London).

Orr, J E, 1996 Talking About Machines: An Ethnography of a Modern Job (Cornell University Press, New York).

Park, R E, 1936, “Human Ecology” Amercian Journal of Sociology 42(1) 1-15.

Scollon, R and Scollon, S W, 2003 Discourses in Place. Language in the Material World (Routledge, London).

Sharrock, W W and Anderson, D C, 1979, "Directional Hospital Signs as Sociological Data" Information Design Journal 1(2) 81-94.

Simmel, G, [1909] 1994, "Bridge and Door" Theory, Culture \& Society 11(1) 5-10.

Sonda, G, Coletta, C and Gabbi, F eds., 2010 Urban Plots, Organizing Cities (Ashgate, London).

Star, S L, 1999, "The Ethnography of Infrastructure" American Behavioral Scientist 43(3) 377-391. 
Star, S L and Strauss, A, 1999, "Layers of silence, arenas of voice: the ecology of visible and invisible work" Computer Supported Cooperative Work 8(1-2) 9-30.

Thibaud, J-P, 2011, "The three dynamics of urban ambiances", in Sites of Sound: Of Architecture and the Ear Vol. 2 Eds B LaBelle and C Martinho (Errant Bodies Press, Berlin), pp 43-53.

Timpf, S, 2002, "Ontologies of Wayfinding: a Traveler's Perspective" Networks and Spatial Economics 2(1) 9-33.

Ureta, S, 2013, "Waiting for the Barbarians: disciplinary devices on Metro de Santiago" Organization 20(4) 596-614.

Varnelis, K ed, 2009 The Infrastructural City (Actar, New York).

Verbeek, P P, 2004 What Things Do: Philosophical Reflections on Technology, Agency and Design (Pennsylvannia State University Press, University Park).

Vertesi, J, 2008, "Mind the Gap: The London Underground Map and Users' Representations of Urban Space" Social Studies of Science 38(1) 7-33. 